\title{
Welcome to volume 9 of Therapeutic Delivery
}

\author{
Hannah Makin* \\ * Author for correspondence: h.makin@future-science.com
}

Happy New Year to all of our readers! Welcome to volume 9 of Therapeutic Delivery. We would like to take the opportunity to look back over 2017, which was another excellent year for us. We thank all our readers, reviewers, authors and Editorial Board members for their continued support and very much look forward to working with all our contributors again in 2018.

First draft submitted: 08 November 2017; Accepted for publication: 08 November 2017; Published online: 8 December 2017

Keywords: biomedicine $\bullet$ drug delivery $\bullet$ health $\bullet$ publications $\bullet$ research

\section{Content Highlights of 2017}

Therapeutic Delivery publishes a diverse range of articles covering key advances in the ever-evolving field of drug delivery. This Foreword looks at some of the most-read content of 2017, at the time of writing this article (November 2017).

\section{Industry Updates}

Our regular Industry Update articles continue to be hugely popular with our readers. These articles provide our readers with a comprehensive update on the industry by summarizing information sourced from company press releases, regulatory and patent agencies, and by covering the latest news on business developments, collaborations, funding, approvals and clinical trials. In 2017, our most-accessed Industry Update was written by one of regular contributors, Peter Timmins from the University of Huddersfield (Huddersfield, UK) [1].

\section{Opinion articles}

Several Editorial-style articles providing a snapshot of issues of topical importance to the field also featured in our most read content in 2017. For example, Lawrence Tamarkin (CytImmune Sciences Inc [MD, USA]) and David Kingston (Virginia Polytechnic Institute and State University [VA, USA]) offered key insights on the timely topic of nanoparticle drug delivery in their Commentary on 'Exposing the tumor microenvironment: how gold nanoparticles enhance and refine drug delivery' [2].

The topic of nanoparticle drug delivery seemed to be very popular with our readers in 2017 , and was covered in many of our published articles throughout the year. On this topic, Serena Mazzucchelli (University of Milan [Milan, Italy]) and Fabio Corsi (University of Milan) also contributed another popular opinion piece. Here, they discussed how nanoparticles could be used for diabetes treatment. This Editorial on 'Diabetes management strategies: can nanoparticles be used to therapeutically deliver insulin?' can be found in 2017's February issue [3].

\section{Review \& Primary Research articles}

Review articles highlighting recent significant advances in research, ongoing challenges and unmet needs in which authors provide a concise and critical appraisal of the subject matter and research articles presenting novel work and discussing important advancements in drug delivery also continue to be very well-received by our readers. One of the journal's most-accessed Review articles of 2017 is one written by Sylvain Martel (Polytechnique Montréal [Quebec, Canada]) on 'Targeting active cancer cells with smart bullets', which discusses how therapeutic agents with propulsion-navigation-homing capabilities may pave the way to new smart delivery agents [4]. Also of popular interest to our readers was one of our Special Report articles written by Mikael Caspersen, Matthias Kuhlmann, 
Karl Nicholls et al. on the important topic of 'Albumin-based drug delivery using cysteine 34 chemical conjugates - important considerations and requirements' [5].

Therapeutic Delivery has also seen published a number of interesting Drug and Device Evaluations. In the September issue of 2017, for example, Jillian Frieder, Dario Kivelevitch and Alan Menter from Baylor University (TX, USA) contributed an interesting literature review on calcipotriene/betamethasone dipropionate aerosol foam as a novel single product combination for the topical treatment of psoriasis [6].

\section{Interviews}

2017 also saw us publish Interviews with two experts in the drug delivery field. For our January issue, we interviewed Tarun Goswami from Amneal Pharmaceuticals (NJ, USA), who is an esteemed member of our journal's Editorial Board. In this interview, we discussed his recent work in the transdermal and oral mucosal drug delivery field and also what his thoughts were on where the field for such alternative drug delivery systems is headed in the future [7].

A recent addition to Therapeutic Delivery's Editorial Board, Nadia Passerini from the University of Bologna (Bologna, Italy), was also interviewed on her area of expertise, which is mainly solid drug delivery systems [8]. Her recently published work at the time, as well as her plans for further research in this area, were discussed in detail throughout the interview.

\section{Editorial Board}

Earlier in the year, we were delighted to promote the esteemed Ajay Banga (Mercer University [GA, USA]), who is an expert in the field of transdermal drug delivery, and David Brayden (University College Dublin [Dublin, Ireland]), an oral drug delivery expert, to Senior Editors on Therapeutic Delivery's Editorial Board.

\section{Special Focus Issues}

We have a number of exciting themed issues in mind for Therapeutic Delivery in 2018. Currently, we are hoping to publish an entire issue dedicated to the applications and challenges of nanotechnology in drug delivery. We also intend to highlight other current and happening themes in the field, for example the emerging and important topic of ocular drug delivery.

Should you be interested in getting involved with either of the themed issues mentioned above, or have any ideas in mind for other topics we could potentially focus on, please do not hesitate to get in touch. We would love to hear your suggestions!

\section{Therapeutic Delivery in the community}

The main aim of Therapeutic Delivery's editorial team is to ensure that we continue to cover all aspects of drug delivery and that the journal remains focused on the key themes and trends in the advancing field. We hope to achieve a strong presence in the scientific community by continuing to reach out to all our valued readers and contributors.

We very much welcome and encourage unsolicited manuscript submissions through the online manuscript processing portal ScholarOne Manuscripts ${ }^{\text {TM }}$ [9]. Prior to submission, we are also happy to assist our potential authors by giving feedback, suggestions and ideas for article proposals. Future Science also continues to partner with Enago [10], which offers pre-submission editing services for our authors.

\section{Article outreach}

We continue to post about our articles on Therapeutic Delivery's Twitter (@fsgtde) [11] and Linkedin [12] social media accounts. However, as higher readership is consistently seen by our articles that have been shared by the authors, I would like to encourage all our journal contributors to share their work via social media to help their work reach the widest possible audience. As social media evolves to become a powerful tool in disseminating scientific research news, we also work with Altmetrics; which continues to help us track and analyse the impact our published articles are having in the community [13].

We are also pleased to continue our partnership with Kudos in 2018, to support our authors in sharing their work and tracking the results of their activities [14].

\section{Demographics of contributors}

As can be seen from Figures 1 and 2, Therapeutic Delivery continues to have a wide reach across the globe. As shown 


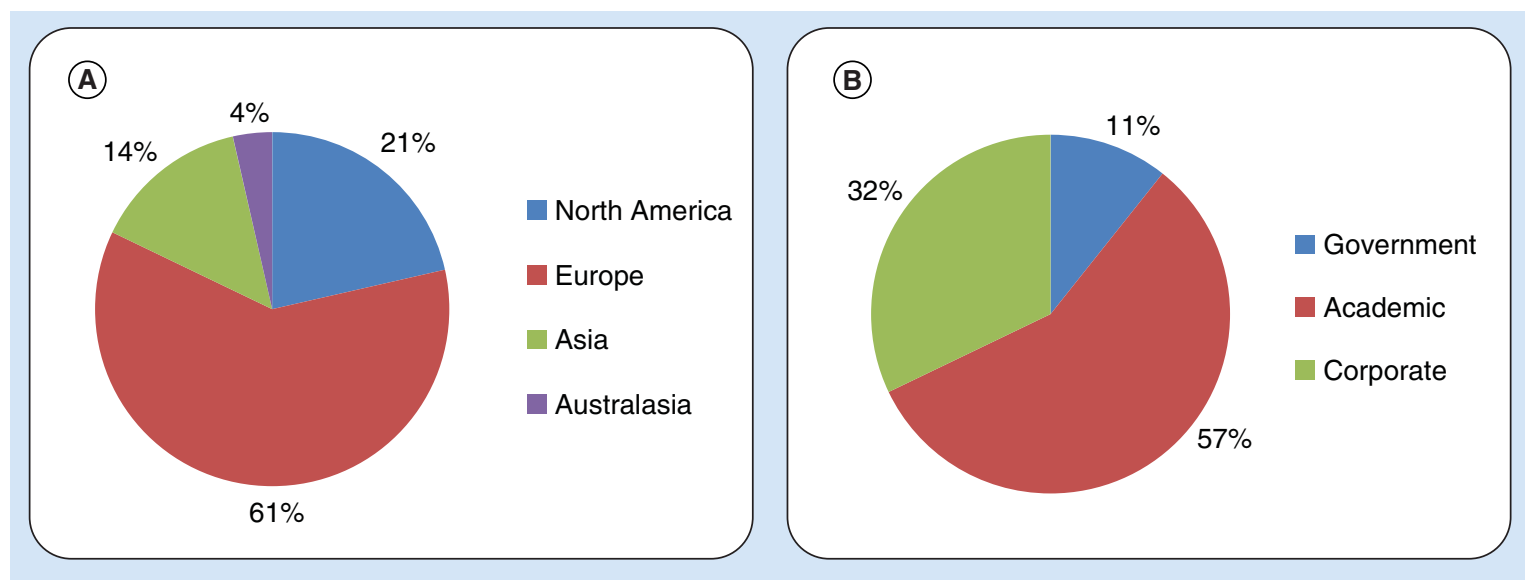

Figure 1. Percentage of subscriptions by (A) geographical location and (B) sector.

Figure 2. Authorship by geographical location.

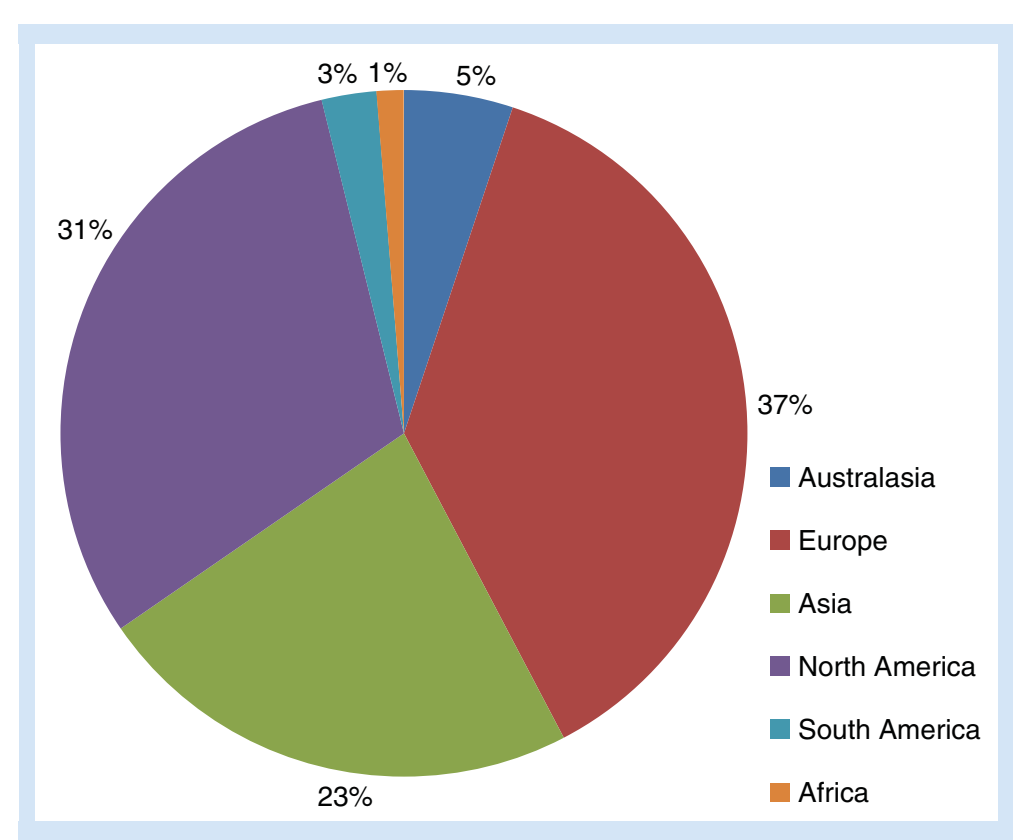

in Figure 1A, the majority of subscribers of the journal are from Europe and North America, however we also see subscribers from the rest of the world, with a noticeable number coming from Asia. While our authors remain spread similarly across the globe between Europe, North America and Asia, we have seen contributions made this year by authors based in Australasia, South America and Africa, which is brilliant to see (Figure 2).

The journal also attracts readers from a variety of working environments, with most of our subscribers being from an academic background (Figure 1B). We strive to work with scientists from both academic and corporate surroundings, but also those from the government.

\section{MedChemNet}

If you have not yet visited Therapeutic Delivery's partnered digital site, MedChemNet [15], we highly recommend that you take a look. MedChemNet is designed to provide experts with a platform to collaborate, showcase their work and share news and their perspectives on the medicinal chemistry field.

MedChemNet, powered by FSG connect, offers an interactive online resource for the scientific community, and membership is completely free of charge. The site complements Therapeutic Delivery by drawing on the important developments and emerging research highlighted in the journal. It also provides a place for our readers to share their thoughts and opinions and discuss topics of interest to the field. 
Financial \& competing interests disclosure

Hannah Makin is an employee of Future Medicine Ltd. The author has no other relevant affiliations or financial involvement with any organization or entity with a financial interest in or financial conflict with the subject matter or materials discussed in the manuscript apart from those disclosed.

No writing assistance was utilized in the production of this manuscript.

\section{References}

1 Timmins P. An industry update: what are the latest developments in the field of therapeutic delivery? Industry Update: 1 st December to 31st December 2016. Ther. Deliv. 8(4), 185-199 (2017)

2 Tamarkin L, Kingston DG. Exposing the tumor microenvironment: how gold nanoparticles enhance and refine drug delivery. Ther. Deliv. 8(6), 363-366 (2017)

3 Mazzucchelli S, Corsi F. Diabetes management strategies: can nanoparticles be used to therapeutically deliver insulin? Ther. Deliv. 8(2), 49-51 (2017)

4 Martel S. Targeting active cancer cells with smart bullets. Ther. Deliv. 8(5), 301-312 (2017)

5 Caspersen MB, Kuhlmann M, Nicholls K et al. Albumin-based drug delivery using cysteine 34 chemical conjugates - important considerations and requirements. Ther. Deliv. 8(7), 511-519 (2017)

6 Frieder J, Kivelevitch D, Menter A. Calcipotriene betamethasone dipropionate aerosol foam in the treatment of plaque psoriasis: a review of the literature. Ther. Deliv. 8(9), 737-746 (2017)

7 Goswami T. An expert's opinion on what lies ahead in the field of alternative drug delivery. Ther. Deliv. 8(1), 1-4 (2017)

8 Passerini N. Emerging technologies in solid drug delivery: an interview with Nadia Passerini. Ther. Deliv. 8(3), 121-124 (2017)

9 ScholarOne Mnauscripts ${ }^{\mathrm{TM}}$ - Therapeutic Delivery. https://mc04.manuscriptcentral.com/fs-tde

10 Future Science - Enago. http://futurescience.enago.com/

11 Therapeutic Delivery Twitter account. https://twitter.com/fsgtde

12 Therapeutic Delivery LinkedIn group. https://www.linkedin.com/groups/3479647

13 Altmetrics. www.altmetric.com/

14 Kudos. www.growkudos.com/

15 MedChemNet. https://www.medchemnet.com/ 